\title{
Using the Canadian Language Benchmarks (CLB) to Benchmark College Programs/Courses and Language Proficiency Tests
}

\section{Lucy Epp and Mary Stawychny}

In this article the authors describe a process developed by the Language Training Centre ${ }^{1}$ (LTC) at Red River College (RRC) to use the Canadian Language Benchmarks (CLB) in analyzing: (a) the language levels used in programs and courses at RRC in order to identify appropriate entry-level language proficiency, and (b) the levels that second language (L2) students need in order to meet college or university entrance requirements based on tests of language proficiency. So far 19 programs and four courses have been benchmarked at RRC. The benchmarking of the programs and courses involved gathering data from various sources at the College and analyzing them by means of CLB descriptors. In addition, a process was developed for using the CLBA and CLB descriptors to benchmark tests: the Canadian Test of English for Scholars and Trainees (CanTEST, 1991) and the Test of English as a Foreign Language (TOEFL). In conclusion, the authors summarize some benefits realized by the benchmarking process. They also address the need to continue to evaluate the results and advise prudent use of the results of these projects.

Dans cet article, les auteurs décrivent un processus développé par le centre de formation linguistique (Language Training Centre - LTC) au Red River College (RRC) permettant d'employer les Niveaux de compétence linguistique canadiens (NCLC) dans l'analyse des (a) échelons linguistiques employés dans les programmes et cours au $R R C$ dans le but d'identifier le niveau linguistique approprié aux débutants et (b) les niveaux que les étudiants en langue seconde doivent avoir atteints pour satisfaire les conditions requises par les évaluations de compétence linguistique menant à l'admission au collège ou à l'université. Jusqu'à maintenant, dix-neuf programmes et quatre cours au RRC ont été ainsi étalonnés. L'étalonnage a impliqué la cueillette de données provenant de diverses sources au Collège, suivie de leur analyse en employant les descripteurs des NCLC. On a également développé un processus permettant le recours à ces descripteurs dans l'étalonnage d'évaluations : le Canadian Test of English for Scholars and Trainees (CanTEST) et le Test of English as a Foreign Language (TOEFL). Un résumé des avantages découlant de l'étalonnage sert de conclusion. 
Les auteurs signalent qu'ils doivent continuer à analyser les résultats et recommandent un usage prudent des résultats de leurs projets.

The Canadian Language Benchmarks (CLB) is

a task-based descriptive scale of language proficiency in English as a second language, expressed in terms of communicative competence as 12 benchmarks (reference points). The CLB describes learners' placement on a language continuum from Benchmark 1 to Benchmark 12 for three skill areas (listening/speaking, reading, and writing). (Citizenship and Immigration Canada [CIC], 1996, p. 1) ${ }^{2}$

The three skill areas addressed by the 1996 CLB document are each subdivided into four subskills as follows:

1. Listening/Speaking

a. following and giving instructions

b. social interchange

c. exchanging information

d. suasion (getting things done)

2. Reading

a. reading instructions

b. reading formatted texts

c. reading unformatted texts

d. reading informational texts-analysis and evaluation

3. Writing

a. information-coping, reproducing

b. formatted text-filling out/constructing

c. unformatted text-describing, conveying messages

d. expressing ideas-analysis and evaluation, persuasion

For each subskill, descriptions of competences, performance conditions, and sample tasks are provided. In addition, the 12 CLB levels are divided into three proficiency stages. Stage I (Benchmarks 1-4) represents basic proficiency, Stage II (Benchmarks 5-8) represents intermediate proficiency, and Stage III (Benchmarks 9-12) represents advanced proficiency.

This article summarizes the process developed to use the CLB in analyzing: (a) the language used in programs and courses at Red River College (RRC) in order to identify appropriate entry-level language proficiency; and (b) the levels second-language (L2) speakers need in order to meet college or university entrance requirements based on tests of language proficiency.

Specifically, from December 1997 to November 2000 the RRC Language Training Centre (LTC) undertook the following projects related to the CLB: (a) 19 RRC programs and four RRC courses were benchmarked in terms of appropriate entry-level language proficiency, and (b) the Canadian Test of English for Scholars and Trainees (CanTEST) and the Test of English as a 
Foreign Language (TOEFL) test were benchmarked in terms of the equivalent CLB levels needed to meet the test levels identified for entry into college or university programs.

Because no model for the process had been developed, a large part of the initial project was the development of the process. Reports summarizing the projects, more detailed information, benchmarking rating instrument forms, and questionnaires are available from the LTC at RRC (see address in note 1).

In order that the results of this project not be used to set up unfair barriers for L2 students who apply for programs, it is important that anyone using these results keep the following considerations in mind. First, the CLBA has been developed as the official assessment tool for the CLB. The highest possible score on this assessment is CLB Level 8. Therefore, when students score at Level 8, they could actually be anywhere in the CLB Levels 8-12 range, because they have reached the ceiling of the test. Furthermore, the CLBA was never meant for high-stakes testing. For example, it is inappropriate as an admissions tool for entrance into postsecondary institutions. Therefore, it is not recommended that CLBA scores be used to determine language readiness for postsecondary studies.

Second, language skills are only one predictor of student success. For example, factors such as training or experience in the field, level of motivation, and study skills also contribute to success. Therefore, CLB levels should not be the only factor considered when determining students' readiness for programs and courses.

A third consideration is the fact that students with lower language proficiency may succeed in programs, but may later have difficulty accessing the job market. In addition, they may be at a disadvantage in the workplace in terms of options and promotions. For this reason it would be to their advantage to be at appropriate language proficiency levels as identified by the project before they enter college or university programs.

\section{Project One: Benchmarking of Programs/Courses ${ }^{3}$ (December 1997-April 1998/February 1999-June 1999/January 2000-November 2000)}

A process was developed to benchmark programs or courses at RRC. In this process the language used in programs and courses was analyzed based on the CLB in order to identify appropriate entry-level language proficiency. The process included selecting programs or courses to benchmark, developing a benchmarking rating instrument, and collecting data from instructors' feedback, classroom observation, students' feedback, and textbook analysis. 


\section{Program Selection}

First of all, programs that had a significant number of $\mathrm{L} 2$ students were given priority. Also, the LTC Advisory Committee was consulted for advice regarding programs that seemed most appropriate for this process.

Next, meetings were arranged with program chairs and coordinators of the selected programs. In these interviews specific questions were asked regarding the success rate of $L 2$ students and the types of problems that were encountered by both staff and students. The process of data collection was discussed as well.

In addition, interviews were conducted with various RRC personnel in the areas of L2 support, tutorial, program evaluation, assessment, admissions, and international education. Outside RRC there was input from the Manitoba Aerospace Human Resources Coordinating Committee and from persons who were benchmarking the Canadian Adult Achievement Test (CAAT). The information gathered helped to develop the appropriate steps for benchmarking and to select programs to be benchmarked.

It was decided that the first term of programs would be the focus of the project. There was general consensus that L2 students who were successful in the first term would probably be successful in the rest of the program. It was also felt that as students participated in programs, they gained both confidence and additional language skills. The programs or courses benchmarked are shown in Table 1.

\section{Development of a Benchmarking Rating Instrument}

Essential to the process was the development of a benchmarking rating instrument. A form was developed for each subskill at the Stage II and III levels of the CLB. Stage I tasks were not identified, as they were considered too basic to be relevant in a college level program. In the instrument itself, tasks representing each subskill at each CLB level (Stages II and III) were identified, and examples of each task were given. For example, for reading, under the subskill reading instructions, a list of tasks-for example, understand simple instructions (CLB Level 6), understand and follow written instructions on school assignments (CLB Level 7)-were chosen (see Appen$\operatorname{dix} A$ ). As much as possible samples were taken from the CLB document itself. An effort was made to make these tasks and examples understandable and relevant to instructors. In addition, for each task there were three choices to be made:

1. Pre-Program. Was this a task that students would have to master before entrance?

2. Program. Was this a task that students would be taught as part of the program/course?

3. Post-Program. Was this a task that students would need to perform in the workplace? 


\section{Programs}

Automotive Technician

Business Administration

Civil Technology

Computer Accounting Technician

Computer Aided Drafting

Computer Analyst Programmer/Information

Systems Technology

Culinary Arts

Developmental Services Worker

Electrical

Aerospace-Related Courses

Aerospace Manufacturing Practices and

Procedures

Dimensional Metrology
Health Care Aide

Heavy Duty Equipment Mechanic

Hotel and Restaurant Administration

Manufacturing Technician

Nursing (Joint Baccalaureate)

Nursing Refresher

Piping Trades

Welding

Wood Processing

Geometric Dimensioning and Tolerancing

Metallurgy and Heat Treatment

The benchmarking instrument was used in group meetings with program instructors (see Data from Instructors below). An abbreviated version of the instrument was developed for use with individual instructors in benchmarking specific courses.

\section{Data from Instructors}

Once programs had been identified, chairs and coordinators were contacted to arrange a two-hour time slot for a meeting with all available instructors. The following information was requested from instructors: course descriptions, samples of a variety of class assignments, timetables, and photocopies of three random pages of each textbook used. All these data were organized and analyzed by the researchers.

In meetings with instructors the purpose of the project was explained and some of the possible benefits were discussed. It was necessary to give a brief overview of the CLB levels, as instructors were generally not familiar with them. Instructors were then asked to brainstorm components of their programs. From this discussion there was input on appropriate language tasks students needed to accomplish for successful participation in programs. Examples included listening to lectures, taking notes, participating in group projects, and giving presentations. Next, researchers used the benchmarking instrument with instructors (see Appendix A). The instrument was introduced by presenting one task to the instructors and asking them as a group to categorize it as pre-program, program, or post-program. This discussion helped instructors to understand what was expected of them as they filled out the forms. Because there was not sufficient time to examine all the CLB 
subskills with the instructors, one or two subskills from each skill area were selected to be the focus for the rating of tasks. Each instructor was given one form for one subskill area (e.g., Listening and Speaking: following and giving instructions), and was given about five minutes to decide individually if each task was pre-program, program, or post-program. Each of these forms was about 1-1.5 pages in length (see Appendix A). After this, researchers led a discussion of instructors' responses, and consensus was reached on which tasks students needed to master before entering the program. This process was repeated with the instrument representing tasks using three or four more forms, each form representing one subskill. About one hour was allowed for observations related to the benchmarking instrument. After the discussion, instructors were asked to hand in their completed forms so that researchers could compare their individual responses with the consensus reached by the group.

This was followed by a general discussion led by researchers about what challenges were faced by L2 students, how they were being addressed, and how they could be better addressed. The pre-program language assessment process was also discussed and suggestions were given. Responses were recorded for analysis.

\section{Data from the Classroom}

Researchers arranged to sit in and take notes on the content of various classes. In addition, the language skills that students used in participating in the class were noted (e.g., notetaking, interacting one on one with other students and/or instructors, interacting in groups, following instructions). Specific terminology as well as phrases and linguistic structures were also noted. All the data were filed for analysis.

\section{Data from Students}

When researchers sat in on classes, they asked instructors for permission to explain the project briefly to the students and to ask L2 students to volunteer their willingness to be interviewed. Meetings were scheduled with each L2 student. Researchers developed a questionnaire for interviews with students. The questions focused on the areas in which the student felt his or her language skills were adequate or inadequate. Students gave feedback on how problems were being addressed or could be addressed more helpfully.

\section{Data from Textbooks}

Readability tests were done on three sample texts from random pages of each textbook provided. Readability formulas included the Flesch Reading Ease, the Flesch-Kincaid Grade Level, the Coleman-Liau Grade Level, and the Bormuth Grade Level. These results were recorded as grade levels (e.g., 
grade 10 , grade 11 , grade 12 ). The results provided a global indication of the level of difficulty of reading in the program.

\section{Using the Data}

Based on all the data available, appropriate entry-level language proficiency for each CLB subskill was identified using CLB descriptors. It was felt that this more specific information might be helpful in analyzing the language needs of each program. In addition, a general CLB level for each skill area was assigned for each program (see Appendix B). For courses, only a general CLB level was identified for each skill area.

A project report for each program and for the aerospace-related courses was prepared, which included appropriate CLB levels for the programs and courses, readability levels of textbooks, summaries of instructor-student feedback, and general observations.

Finally, based on all the data gathered, a report of recommendations and suggestions for RRC was written. It included not only the appropriate CLB levels for entry-level language proficiency for programs or courses, but also some of the general observations that emerged from the research. Various implications were noted, a summary of suggestions for instructors was included, and general recommendations were made for RRC programs. Also, more specific suggestions were made in the light of the data examined in the project. These suggestions related mainly to assessment or admissions procedures and the implementation of more appropriate language proficiency assessment for prospective L2 students.

The benchmarking process itself was found to be helpful in identifying both the strengths and weaknesses of the present system in working with L2 students. RRC intends to use the information gathered to inform and improve assessment or admissions procedures as they relate to $\mathrm{L} 2$ students. The information gathered could also help in choosing appropriate content for preparation programs designed for L2 students who plan to enter RRC. In addition, the information has the potential to improve the chances of success for $\mathrm{L} 2$ students enrolled in programs or courses at RRC.

\section{Project Two: Benchmarking of the CanTEST/TOEFL 4 (February 1999-June 1999)}

The goal of the second project was to determine the CLB levels that corresponded with the scores required on the CanTEST and the TOEFL in terms of accessing college and university programs. Both the CanTEST and the TOEFL are tests of English language proficiency developed to determine applicants' adequacy of language proficiency for admission to academic programs in colleges and universities.

The CanTEST measures four skill areas (reading, writing, listening, and speaking) and scores are reported in Band Levels, with $5.0+$ being the highest 
score. Based on information from the University of Manitoba, University of Winnipeg, and the CanTEST Project Office at the University of Ottawa, it was found that colleges and universities generally recognize scores in the range of Band Level 4.0 to 5.0 as sufficient for entrance into programs.

The TOEFL (paper-based) consists of three sections (listening comprehension, structure and written expression, and reading comprehension). Based on an environmental scan of 20 colleges and universities (undergraduate programs) across Canada, it was found that TOEFL entrance requirements range from 500 to 600 . In 16 out of 20 cases, the required TOEFL scores range from 550 to 580 . Based on this information, it was decided that a TOEFL score of 550 to 580 would be considered the score generally required to meet college or university English-language proficiency entrance requirements. Only two universities reported minimum scores for Sections 1-3 of the TOEFL. In both cases the minimum score per section was 50 . An average score of 50 per section would represent an overall score of 500, well below the TOEFL score required by most colleges and universities. Because an average of 55-58 on each section would result in the overall score of 550-580, it was decided that 55-58 would represent the score generally required on each section of the TOEFL. In addition, a Test of Written English (TWE) may be administered. The highest score on this test is 6 , and colleges and universities that require a TWE score usually set the level for admission at around 5 out of 6 .

\section{Comparison of Scores}

Comparisons between scores on the CLBA and the TOEFL and CanTEST were made. The CLBA was developed to assess ESL students based on communication tasks that represent CLB Levels 1-8 (Stages I [Levels 1-4] and II [Levels 5-8]) as described in the CLB document, Norton Peirce, \& Stewart, 1997). Instructors in the advanced ESL programs at RRC discussed the project with students and asked for volunteers to be tested. Forty-one students volunteered to be tested, 30 for the CanTEST/CLBA comparison, and 11 for the TOEFL/CLBA comparison. The two assessments (CanTEST/ CLBA and TOEFL/CLBA) were administered to student volunteers within two weeks of each other.

Trained assessors administered official CLBA assessments to all the students. Permission to administer an official CanTEST was given to RRC by the CanTEST Project Office at the University of Ottawa. All four sections of the test were administered following the test procedures required. The writing and speaking sections were scored by trained and experienced assessors of the CanTEST. The test results were sent to the University of Ottawa for confirmation.

A paper-based practice TOEFL test (Test Form TPK98) published by the Educational Testing Service was administered to students and scored by LTC 
instructors following official TOEFL rules based on guidelines published in the Test Preparation Kit (Educational Testing Service, 1998b).

\section{Observations Based on Score Comparisons}

A number of factors affected the ability to generalize based on score comparisons:

1. A relatively small sample of students ( 30 on the CLBA/CanTEST and 11 on the CLBA/TOEFL) was tested.

2. The CLBA is a different test than the TOEFL and CanTEST.

- The CLBA uses general settlement language tasks to assess language levels, whereas the TOEFL and CanTEST test proficiency using college- or university-level academic tasks.

- The CLBA presently combines speaking and listening, whereas the TOEFL and CanTEST do not.

- The CLBA assesses discourse writing that relates to settlement issues (e.g., writing a letter, a memo). The CanTEST requires a more academic writing task (essay-writing), whereas Section 2 of the TOEFL tests students' ability to complete or correct rather academic sentences in isolation, in addition to the essay-writing.

3. The highest possible score on the CLBA is CLB Level 8. Because most students scored near the highest level or surpassed it, we can predict that some of them could have scored at CLB Level 9 or 10 (or more) if they had had the opportunity. Students who seemed capable of moving beyond Stage II were indicated by an $8+$. In most cases students who received $8+$ on the CLB scored in the range of 500 to 550 on the TOEFL and 3.0 to 4.5 on the CanTEST. That is, they were not generally at the ceiling of the test. Thus it seems that the TOEFL and CanTEST generally test a higher level of language proficiency than does the CLBA.

Based on these findings, it was felt that an in-depth analysis of the TOEFL and CanTEST using CLB descriptors was necessary. It was decided that this analysis would be done on the TOEFL and the CanTEST that had been administered to students.

\section{Analysis of TOEFL and CanTEST Using CLB Descriptors}

\section{Speaking/Listening}

The fact that speaking and listening were combined in the 1996 CLB document posed a problem, because these skills are separated in the TOEFL and CanTEST. To address this problem, researchers separated listening and speaking descriptors at each relevant CLB level. Speaking and listening descriptors were then matched respectively with available descriptors of speaking and listening levels on the CanTEST (The CanTEST Oral Interview, 1998). In the case of the TOEFL test, speaking was not tested, and listening descriptors are not published. 
Each passage of the listening comprehension section of the TOEFL and the CanTEST was analyzed sentence by sentence in terms of the CLB stage it represented and the level of difficulty of the structures. In addition, each passage was matched with CLB descriptors in terms of the language skills necessary for achieving the required scores. Finally, each question was analyzed as it related to each passage. The type of question (e.g., specific information, prediction) was determined and matched with CLB descriptors.

Based on the analysis of the data gathered, each passage was assigned a CLB level. Many CLB descriptors seem to assume that the learner is able to function equally well at a task both as a speaker and as a listener. For example, at CLB Level 8, the following descriptor for Listening and Speaking states, "Understands and uses sufficient concrete and abstract vocabulary, idioms, and colloquial expressions to follow and relate stories of general popular interest" (CIC, 1996, p. 50). Because learners usually acquire listening skills earlier than speaking skills, it was decided that in terms of listening skills, preference would be given to a lower rather than a higher CLB level.

Using all the data that had been gathered and analyzed, researchers assigned a general Listening/Speaking CLB level needed to attain the required scores of 55-58 on the TOEFL Listening and 4.0-4.5 on the CanTEST (see Appendix C).

\section{Reading}

First, readability formulas were used to assess the levels of difficulty of the reading texts on the TOEFL and CanTEST. The Flesch Reading Ease and the Flesch-Kincaid Grade Level were used for both. For the CanTEST the Coleman-Liau Grade Level and the Bormuth Grade Level were also used. These results were recorded as grade levels (e.g., grade 10, grade 11, grade 12). The results provided a global indication of the level of difficulty of the reading texts.

Each TOEFL and CanTEST reading passage (unformatted) was analyzed sentence by sentence to determine the CLB stage level it represented and the difficulty of the structures. In addition, all the reading passages were matched with CLB descriptors in terms of the language demands of college or university entrance requirements. Then each question related to each passage was analyzed in terms of structural complexity. The type of question was determined and matched with CLB descriptors.

Based on the analysis of the data gathered, each reading passage was assigned a CLB level. Using all the data that had been gathered and analyzed, researchers assigned a general equivalent reading CLB level needed to attain the required scores of 55-58 on the TOEFL Reading and 4.0-4.5 on the CanTEST (see Appendix C). 


\section{TOEFL Structure and Written Expression (Section 2)}

The TOEFL Structure and Written Expression (Section 2) was analyzed item by item in terms of the level of difficulty, the CLB stage it represented, the type of sentence, and the grammatical structure being tested. CLB descriptors that referred to the types of grammatical structures tested were identified. It was noted that CLB descriptors refer to grammatical structures produced by the students in the context of continuous prose, whereas Section 2 of the TOEFL tests the grammatical structures of sentences in isolation. On the TOEFL students do not need to produce the sentences, but rather complete or correct them. As a result, it seems that the CLB descriptors reflect a more complex use of grammatical structure than does Section 2 of the TOEFL.

Based on the analysis of the data, researchers assigned a general CLB level needed needed to attain the required scores of 55-58 on Section 2 of the TOEFL (see Appendix C).

\section{Essay-Writing}

The researchers analyzed the types of essays required by the CanTEST and the TWE (Test of Written English) of the TOEFL. Both tests require students to write essays on academic topics. The CLB document (1996), on the other hand, describes different types of writing tasks required at each level.

Descriptors of levels of proficiency in essay-writing are available with both the CanTEST (Guidelines for Administering and Scoring CanWRITE, 1998) and the TOEFL (TOEFL 1998-1999 Information Bulletin for Computer-Based Testing, Educational Testing Service, 1998a). Relevant CLB writing descriptors were matched with both the CanTEST and TOEFL essay-writing descriptors. It was noted that tasks suggested at the lower level CLB descriptors were significantly easier than the essay-writing tasks required by the TOEFL or CanTEST. For example, a task at CLB Writing Level 6 is to describe a person's strengths and attributes as a friend. However, a task at CLB Writing Level 11 is to write an expository text in which problems and issues are presented, explored, analyzed, explained, and evaluated. L2 students at any level would perform much better on the CLB Level 6 task than on the CLB Level 11 task. The TOEFL and CanTEST, on the other hand, require all students to perform on the same task (writing an analytical essay) regardless of their level of language proficiency. Based on these differences, researchers compared how students at any given CLB level functioned when writing a CanTEST or TOEFL essay. It was concluded that although a student might do quite well on a CLB Level 6 writing task, it was necessary to determine how that same student might do on a CanTEST or TOEFL essay. Based on all these considerations, researchers assigned a general CLB level needed to attain required scores in writing (see Appendix C). 


\section{Implications}

It is hoped that this process of benchmarking programs and assessment tools will result in more effective pre-program language proficiency assessment for L2 students. As mentioned above, it is important that the results of these projects not be used to set up unfair barriers for L2 students who wish to enter colleges and universities. Language proficiency is not the only factor that determines the success of L2 students in college or university programs. For example, factors such as training and/or experience in the field, level of motivation, and study skills also contribute to success. In addition, it should be noted that there is currently only one official CLB assessment tool, the CLBA. The highest possible score on this assessment is Level 8 . Therefore, when students score at CLBA Level 8 , they could actually be anywhere in the CLB Levels 8-12 range because they have reached the ceiling of the test. In addition, the CLBA tasks are not necessarily representative of tasks students would encounter in college or university. It is therefore not recommended that CLBA scores be used to determine language readiness for L2 students who wish to study in colleges and universities. It is also important to remember that although the CLB levels assigned in these projects were based on the data available, it will be necessary to track students entering RRC with CLB levels in order to validate the results.

It should be noted that the process of benchmarking programs and courses was unexpectedly beneficial to RRC. Because a great deal of interaction occurred between the LTC staff and other RRC staff in the various programs involved, more networking has been facilitated. Also, the process has raised awareness of L2 needs in regular academic programs. Staff members involved have become more aware of resources that are available and have consulted with each other more freely. In addition, as a result of these projects, some recommendations that would enhance the learning experience of L2 students at RRC have been made.

\section{Notes}

${ }^{1}$ Language Training Centre, Red River College (downtown campus), Suite 300-123 Main St., Winnipeg, MB, CANADA R3C 1A3.

${ }^{2}$ the CLB Working Document (1996) was replaced by the CLB 2000 in September 2000; in the later document listening and speaking skills were separated.

${ }^{3}$ Funded by the Manitoba Department of Culture, Heritage and Citizenship, Manitoba Labour, and Citizenship and Immigration Canada.

${ }^{4}$ Funded by the Manitoba Department of Culture, Heritage and Citizenship, Manitoba Labour, and Red River College. 


\section{The Authors}

Lucy Epp has an MEd from the University of Manitoba. She has taught EFL/ESL in Japan and the United States and is presently an instructor and researcher at the Language Training Centre at Red River College in Winnipeg, Manitoba.

Mary Stawychny has a post-baccalaureate degree in education from the University of Manitoba and is an instructor in ACCESS Model Programs at Red River College. She has worked extensively in assessment and instruction of ESL students.

\section{References}

Citizenship and Immigration Canada. (1996). Canadian language benchmarks: English as a second language for adults/English as a second language for literacy learners. Working Document. Ottawa: Ministry of Supply and Services Canada.

Educational Testing Service. (1998a). TOEFL 1998-1999 information bulletin for computer-based testing. Princeton, NJ: Author.

Educational Testing Service. (1998b). TOEFL test preparation kit (2nd ed.). Princeton, NJ: Author.

Guidelines for administering and scoring CanWRITE - The CanTEST writing examination. (1998). Ottawa: CanTEST Project Office, University of Ottawa.

Norton Peirce, B., \& Stewart, G. (1997). The development of the Canadian Language Benchmarks assessment. TESL Canada Journal, 14(2), 17-31.

The Canadian test of English for scholars and trainees (CanTEST): Information booklet for test candidates. (1991). Ottawa: CanTEST Project Office, University of Ottawa.

The CanTEST oral interview: Guidelines for conducting and scoring the CanTEST oral interview. (1998). Ottawa: CanTEST Project Office, University of Ottawa. 


\section{Appendix A}

A sample from the benchmarking rating instrument developed to rate language tasks in programs at RRC.

Benchmarking Rating Instrument for Canadian Language Benchmarks

Reading

\begin{tabular}{llll}
\hline $\begin{array}{l}\text { Pre- } \\
\text { Program }\end{array}$ & $\begin{array}{l}\text { Program } \\
\text { Content }\end{array}$ & $\begin{array}{l}\text { Post- } \\
\text { Program }\end{array}$ & 1. Instructional Text \\
\hline
\end{tabular}

Understand simple instructions

- chemical product use and warning labels

Understand and follow written instructions on school

assignments

- read the first chapter of the text and be ready to discuss it in class next Monday

Understand and follow simple instructions on how to operate a piece of equipment

- how to use a photocopier

Understand and follow a wider range of written instructions

- instructions related to an assignment

$\Rightarrow$ how to do research in the library

Understand and follow written instructions of medium complexity

- how to outline/research/write/edit proofread an essay or report

- how to word-process, save and print a research report with footnotes and references

Extract and present comprehensively and coherently, in point form, instructions from a continuous prose text

- how to use an on-line computer or CD-ROM computer encyclopedia

Understand and follow complex and extensive specialized written instructions in own academic field

- how to use computer software to do a spreadsheet

- how to program a VCR/stereo/microwave

Understand and follow complex and extensive written instructions of any kind

- how to design, conduct, calculate, and interpret a scientific experiment

- how to fill out complex application/reporting forms 


\section{Appendix B}

Appropriate CLB Levels for Entry-Level Language Proficiency for RRC Programs

\begin{tabular}{lccc}
\hline Program & $\begin{array}{c}\text { Listening/ } \\
\text { Speaking }\end{array}$ & Reading & Writing \\
& $8 / 9$ & $8 / 9$ & $7 / 8$ \\
\hline Automotive technician (certificate) & $8 / 9$ & $9 / 10$ & $8 / 9$ \\
Business administration & $8 / 9$ & $9 / 10$ & 8 \\
Computer accounting technician & $8 / 9$ & 9 & $7 / 8$ \\
Computer-aided draftng & & & \\
Computer analyst programmer/information & $8 / 9$ & 8 & $7 / 8$ \\
systems technology & $8 / 9$ & $8 / 9$ & $7 / 8$ \\
Culinary arts & 8 & 9 & $7 / 8$ \\
Electrical (certificate) & $7 / 8$ & $7 / 8$ & $6 / 7$ \\
Health care aide & $8 / 9$ & $8 / 9$ & $7 / 8$ \\
Heavy duty equipment mechanic (certificate) & 9 & $9 / 10$ & $8 / 9$ \\
Hotel and restaurant administration & $8 / 9$ & $7 / 8$ & 8 \\
Manufacturing technician & $9 / 10$ & 9 & \\
Nursing (joint baccalaureate) 9 & 8 & 9 & $7 / 8$ \\
Piping trades (certificate) & 8 & 8 & 7 \\
Welding & $8 / 9$ & 8 & $7 / 8$ \\
Wood processing (diploma) & & & \\
The following levels are based on CLB 2000*: & & & \\
\hline
\end{tabular}

Speading Listening Reading Writing

Civil technology

Developmental services worker

Nursing refresher

$\begin{array}{cccc}8 & 8 / 9 & 9 & 7 / 8 \\ 8 & 8 / 9 & 8 / 9 & 8 \\ 8 / 9 & 8 / 9 & 9 & 7 / 8\end{array}$

Appropriate CLB Levels for Entry-Level Language Proficiency for RRC Courses

$\begin{array}{ll}\text { Course } & \begin{array}{l}\text { Listening/ Reading Writing } \\ \text { Speaking }\end{array}\end{array}$

Aerospace manufacturing practices and

procedures

Dimensional metrology

Geometrical dimensioning and tolerancing

Metallurgy and heat treatment

$\begin{array}{lll}9 & 10 & 9 \\ 9 & 10 & 9 \\ 9 & 10 & 9 \\ 9 & 10 & 9\end{array}$

${ }^{*}$ Canadian Language Benchmarks 2000 was published in September, 2000. In this document listening and speaking skills were separated. The last three programs listed above were benchmarked in Fall 2000, and therefore reflect that change. 


\section{Appendix C}

Canadian Language Benchmark Levels Needed for CanTEST Band Levels

\begin{tabular}{lcc}
\hline Sections of the CanTEST & $\begin{array}{c}\text { CanTEST Band } \\
\text { Scores }\end{array}$ & $\begin{array}{c}\text { Corresponding } \\
\text { Benchmark } \\
\text { Levels }\end{array}$ \\
\hline Listening & 4.0 & $7 / 8$ \\
Reading & 4.5 & $8 / 9$ \\
& 5.0 & $9 / 10$ \\
Writing & 4.0 & $7 / 8$ \\
& 4.5 & $8 / 9$ \\
Speaking & 5.0 & $9 / 10$ \\
& 4.0 & 8 \\
& 4.5 & 9 \\
& 5.0 & 10 \\
\hline
\end{tabular}

Canadian Language Benchmark Levels Needed for TOEFL Scores (paper-based)

\begin{tabular}{lcc}
\hline TOEFL Section & $\begin{array}{c}\text { Successful } \\
\text { TOEFL Score }\end{array}$ & $\begin{array}{c}\text { Corresponding } \\
\text { Benchmark } \\
\text { Levels }\end{array}$ \\
\hline Section 1: Listening Comprehension & $55-58$ & $8 / 9$ \\
Section 2: Structure and Written Expression & $55-58$ & $8 / 9$ \\
Section 3: Reading Comprehension & $55-58$ & $8 / 9$ \\
Test of Written English (Essay) & $4-4.5$ & $6 / 7$ \\
& $5-5.5$ & $8 / 9$ \\
& 6 & $10+$ \\
\hline Overall TOEFL Score & $550-580$ & $8 / 9$ \\
\hline
\end{tabular}

